\title{
LUT
}

University

\section{Waking the Sleeping Beauty: Swarovski’s Open Innovation Journey}

Dabrowska Justyna, Lopez-Vega Henry, Ritala Paavo

This is a Author's accepted manuscript (AAM) version of a publication

published by RADMA and John Wiley \& Sons Ltd.

in R\&D Management

DOI: $10.1111 / \mathrm{radm} .12374$

Copyright of the original publication: (C) 2019 RADMA and John Wiley \& Sons Ltd

Please cite the publication as follows:

Dabrowska, J., Lopez-Vega, H., Ritala P. (2019) Waking the Sleeping Beauty: Swarovski's Open Innovation Journey. R\&D Management, Vol. 49, iss. 5, pp. 775-788. DOI: 10.1111/radm.12374

This is the peer reviewed version of the article, which has been published in final form at https:// doi.org/10.1111/radm.12374. This article may be used for non-commercial purposes in accordance with Wiley Terms and Conditions for Use of Self-Archived Versions.

This is a parallel published version of an original publication. This version can differ from the original published article. 


\section{Waking the Sleeping Beauty: Swarovski's Open Innovation Journey}

Even in today's turbulent business environment, there are companies in many industries that have enjoyed decades of relatively undisturbed success. However, eventually, after such prolonged periods of calm, existing market positions are challenged. We describe such companies as 'Sleeping Beauties' and discuss how they can reinvent themselves through opening up of their boundaries and moving from compartmentalized exploitation and exploration efforts to a more dynamic ambidexterity model. We analyze Swarovski's open innovation journey in this regard, instigated as a response to recent changes in its business environment. Our analysis of this process offers useful insights for companies struggling with similar problems.

Keywords: open innovation; closed innovation; organizational rigidity; ambidexterity; ecosystems; capability rigidity; structural rigidity; case study; Swarovski

\section{Introduction}

Every new era offers new possibilities for action and development. Development never stands still. Innovations in one field inevitably lead to innovations in others. One must remain alert at all times, always ready to make the very best use of what emerges.

Daniel Swarovski (1862-1956), founder of Swarovski

While all industries go through disruption and periods of dramatic change, some companies have managed to maintain their identities and business models relatively unchanged - even over decades, and sometimes hundreds of years. A common feature of such companies is their reliance on a strong underlying technology, their access to key resources, a unique production process, and related complementary assets such as brand and distribution channels. For example, Möet \& Chandon, a luxury beverage producer established in 1743 , continues to produce highquality champagne in a very different environment from when it was founded. Similarly, Lego, founded in 1932, depends on a business model and key idea of detachable building blocks and related products. On the other hand, it is well known that many incumbent firms also fail, despite decades of market leadership, as they suffer from disruption brought by new technologies and processes, market changes, regulation, and new competitors (Gilbert, 2005). Known examples 
of those companies that were built on seemingly everlasting competitive advantages and which failed to recognize new opportunities include Kodak, Nokia, Smith Corona, and Blackberry (O’Reilly and Tushman, 2016; Tripsas and Gavetti, 2000).

What sets successful companies apart from those who fail in this regard? A key explanation is very often related to their past superior performance and resulting organizational rigidity (Bröring and Herzog, 2008; Gilbert, 2005). O'Reilly and Tushman (2016) refer to the 'success syndrome' to describe company structures and a company culture that are inert to change. Continued success often leads to path-dependency, which increases over time based on positive and self-reinforcing feedback mechanisms (Sydow et al., 2009). Furthermore, superior technological competences become legitimized in the firm over time, gathering support and resources (Danneels et al., 2017). When this situation continues for too long, a change of trajectory can become extremely difficult if not impossible as core capabilities turn into core rigidities (Leonard-Barton, 1992). In this paper, we identify the incumbent companies having this tendency as 'Sleeping Beauties'. These companies have been able to: i) hone their processes and technologies over decades; ii) experience extended periods of low competition and relatively undisturbed success in the past; and iii) have a competitive advantage based on a strong product, technology, or brand and, thus, occupy a solid position in their market. We argue that companies with these tendencies encounter two types of rigidity ${ }^{1}$ : structural rigidity and capability rigidity. In the context of our study, structure refers to the firm's internal and external organizational boundaries (Lifshitz-Assaf, 2017; Menon and Pfeffer, 2003), and capabilities refer to the firm's abilities to explore and exploit (O’Reilly and Tushman, 2016).

We connect solutions to overcome the rigidity trap to two particular, yet interconnected, strands of literature: open innovation and organizational ambidexterity. First, the literature on open innovation has helped to explain how firms are able to renew themselves and improve their innovation outcomes by transferring knowledge across organizational boundaries. Particularly highlighted in this regard are inbound and outbound knowledge flows, as well as a "coupled mode', where firms partner with external actors (Enkel et al., 2009; West and Bogers, 2014). Recent evidence also shows that large firms also benefit to a great extent in employing open innovation practices in internal organizing (Moellers et al., 2018). Second, the organizational

\footnotetext{
${ }^{1}$ Scholars have discussed both organizational inertia and rigidities, oftentimes in a synonymous fashion. However, the former has been used in more population-level analyses, while the latter focues on the firm (see Rawley, 2010), which is our level of analysis. In this study we will use the concept of rigidity to discuss the transformation challenges of the firm that result in past success and the reinforcement of its current structures and capabilities.
} 
ambidexterity literature has studied extensively how firms could combine the need to exploit their current capabilities and focus on efficiency while exploring new ways of operating and to innovate (Duncan, 1976; Tushman and O'Reilly, 1996; Birkinshaw and Gupta, 2013; Papachroni et al., 2016).

Together, open innovation and organizational ambidexterity provide feasible lenses through which to examine how companies can overcome the 'rigidity trap' embedded in long-standing success. There is some recent evidence demonstrating how ambidextrous organizing principles - and exploitation and exploration - are linked to open innovation. These studies have established that ambidextrous organizing helps in the implementation of open innovation (Giannopoulou et al., 2011) or vice versa (Mortara and Minshall, 2011). Also, it is suggested that changing the focus between exploitation and exploration is partially aligned with closed and open innovation models (Bröring and Herzog, 2008) and that open innovation and ambidexterity are more generally correlated at the system level (Ferrary, 2011). However, beyond these findings, the linkage between the two phenomena has not been examined in the context of organizational transformation. This is somewhat surprising given the parallel themes included in these streams. For instance, open innovation research has provided a lot of evidence on how companies open up their boundaries and structures in the attempt to improve their innovation outcomes (Bogers et al., 2017; DiMinin et al., 2010; Zobel and Hagerdoorn, 2018), while organizational ambidexterity scholars have also provided a lot of evidence of the structural solutions required for innovation and renewal (O'Reilly and Tushman, 2004; Hansen et al, 2018). Furthermore, open innovation scholars have discussed the required capabilities (including e.g. processes, systems, routines) for organizational transformation (Chiaroni et al., 2010; Lifshitz-Assaf, 2017; Wikhamn and Styhre, 2017; Zynga et al., 2018), and ambidexterity scholars have also examined how companies change the way they organize exploitation and exploration activities over time (Danneels et al., 2017; Shibata et al., 2018). Given these overlaps, we argue that there is a lot of potential benefits in combining the two views. Therefore, we see both a major research gap as well as a research opportunity in examining how mature firms can overcome organizational rigidity by going through a transformation to open innovation using organizational ambidexterity mechanisms.

To examine this research question empirically, we rely on a single case study, documenting the open innovation transformation by Swarovski. Swarovski is a family-run, independent business, which was founded in Austria in 1895 and is run by the fifth generation of family members. 
Swarovski designs, manufactures, and sells the highest quality crystal, genuine gemstones, created stones, and finished products such as jewellery, accessories, and lighting solutions. It is a prime example of a 'Sleeping Beauty' company which had enjoyed a unique technological advantage built over a long period of time and has awakened to an industry transformation embracing change while keeping its core intact. In Swarovski's case, this technological advantage remained mostly unchanged for a century and allowed the company an almost uncontested position in its markets. However, Swarovski is not immune to the sweeping and accelerating changes in global competition that affect all industries, and the effects of digitalization and the econcomic crisis. To develop new products across different sectors, Swarovski has transformed its own R\&D model into a more open innovation approach that continuously integrates external partners. In our view, the case of Swarovski provides some important lessons for how mature companies can escape the looming rigidity trap which can haunt especially the most successful and dominant players (Gilbert, 2005).

More broadly, our case provides valuable insights for understanding the transition to open innovation (e.g. Chiaroni et al., 2010; Di Minin et al., 2010; Zynga et al., 2018), which we show involves numerous domains. Swarovski's knowledge search was transformed from a rather unilateral search and acquisition of external knowledge to a more proactive and reciprocal ecosystem engagement. We identify relevant innovation problems and sources of rigidity, external triggers of change, and the mechanisms employed to overcome these challenges. In particular, we find that Swarovski has been able to overcome its structural rigidities by changing from boundary-preserving to boundary-spanning mode, and finally to boundary-expanding mode. Furthermore, at the same time, Swarovski has unravelled the capability rigidities by changing from static ambidexterity to structural ambidexterity, and finally to dynamic ambidexterity.

Our results contribute to the innovation and $R \& D$ management literature by demonstrating the challenges of organizational rigidity and the ways firms can overcome these challenges through reconfigurations of their internal and external boundaries as well as how exploitation and exploration activities are managed (Martin, 2016). Furthermore, these results represent the first attempts to analyse organizational transformation combining open innovation and ambidexterity perspectives, providing complementary insights to both fields of study. For practitioners, the case of Swarovski exemplifies the transformation to open innovation in mature companies and shows how such Sleeping Beauties can convert their structural and capability rigidities into a 
dynamic and ambidextrous model for the creation of innovation and the conduct of $R \& D$ activities.

\section{Conceptual background: Organizational rigidity, open innovation, and organizational ambidexterity}

Organizational rigidity is the outcome of decades of tinkering, development, and trial-and-error activity by dominant companies (Zollo and Winter, 2002; Danneels et al., 2017). Organizational

rigidity is a firm-level concept that explains how and why it becomes difficult and costly to change organizational structures, contracts, and routines (Kaplan and Henderson, 2005; Rawley, 2010). In this study, we identify two types of rigidity: structural rigidity and capability rigidity. The former is related to both the internal and external structures and the relationships of the firm (cf. Hannan and Freeman, 1984), while the latter relates to routines of the organization, how they are designed, and how they drive exploration and exploitation processes (cf. Gilbert, 2005).

\subsection{Structural rigidity and open innovation}

In the context of innovation, structure refers to how the company coordinates its innovation activities using, for example, specialized R\&D teams, well-honed innovation processes, and programs to manage external alliances and partnerships. It also includes hierarchy and administrative issues - in other words, the organizational form. The organizational form affects how ideas, inventions, and innovations are managed, how power and reporting relationships are distributed, and what forums and platforms are available for knowledge sharing. Both coordination and organizational issues have been widely discussed in the open innovation literature, where the role of both internal and external structures, as well as knowledge flows, have been highlighted as barriers to or drivers of innovation (Enkel and Gassman, 2009; Chiaroni et al., 2010; Moellers et al., 2018). Finally, structure includes the organizational boundaries to innovation activities (cf. Zobel and Hagedoorn, 2018) - that is, which groups of actors are playing an active part in the innovation.

At best, organizational structures are able to improve innovation activities and the involvement of external actors in those activities (e.g. Chiaroni et al., 2010). However, continued success is often accompanied by structural rigidity built over time in the firm's internal and external organizational structure and organizational boundaries (Hannan and Freeman, 1984). Internal 
structural rigidity results in team structures, divisional organization, and the chain of command rarely changing or being questioned. External rigidity means that although there may be some level of external collaboration, new suppliers and partners are rarely adopted, and the company relies on existing partnerships honed over years of collaboration. It has implications also for company boundaries: new knowledge from inside the firm or outside of it rarely crosses them. This ensures the status quo but renders the organization structurally rigid to respond to renewal needs and to grasp new opportunities (Chesbrough, 2003, Chiaroni et al., 2010).

Paradoxically, the main reasons for structural rigidity are market success (Hannan and Freeman, 1984) and firm longevity (Sydow et al., 2009). As the years pass, successful companies tend to grow in size and complexity (e.g. reporting relationships, teams, management hierarchy) (Sydow et al., 2009). It is difficult to scale up operations while retaining the level of simplicity of a start-up - a problem frequently discussed in the new venture literature. Indeed, if the company's structures are overly compartmentalized and rigid, it will be difficult to change and achieve knowledge transfer across boundaries and across silos (Lifshitz-Assaf, 2017).

In terms of breaking the structural rigidity, the open innovation literature has provided a powerful narrative of organizational transformation. Originally, Chesbrough (2003) observed the major transition from closed innovation to open innovation by large companies that were seeking to find new and more connected ways to innovate. In closed innovation, companies rely on in-house $R \& D$, and unutilized internal ideas and technologies remain confidential and confined to the research labs since they do not correspond to the current market. Xerox's Palo Alto Research Center is a classic example of a company that got trapped in its own organizational rigidity (Chesbrough, 2003). As open innovation has gained the interest of companies involved in collaborative $\mathrm{R} \& \mathrm{D}$, scholars have highlighted different mechanisms to implement open innovation (c.f. Bogers et al., 2017; Gassmann et al., 2010; Salter et al., 2014).

Recently, the open innovation research has focused on the evolution of collaboration from closed innovation towards open innovation in networks and ecosystems and including an increasing breadth of strategic interactions with a variety of external stakeholders (Altman and Tushman, 2017; Radziwon and Bogers, 2018; Rohrbeck et al., 2009). Despite previous strategies to cope with open innovation, companies in mature industries, such as food, construction, mining, and manufacturing, continue to experience difficulties when trying to implement open innovation (Salter et al., 2014). For example, Lindt \& Sprüngli has taken the decision to maintain its closed innovation model and use open innovation only when the necessary capabilities are not available 
internally (Manzini et al., 2017). Lindt \& Sprüngli keeps most of its innovation in-house and core products unchanged and relies on its unique recipe, brand recognition, and loyal customer base. A contrasting example is Fiat's research centre, which adopted open innovation during a resource rationalization and crisis period (Di Minin et al., 2010). In Fiat's case, the adoption of open innovation benefited from a dedicated open innovation function and the careful planning of the technology transfer. Another example of transition from closed innovation to open innovation is the Italian cement company Italcementi. The firm operates in an asset-intensive, low-tech, and mature industry and moved to open innovation by creating independent units to manage open innovation projects using its social network of open innovation champions and extending its existing innovation process (Chiaroni et al., 2010). These studies highlight several factors crucial for the transition to open innovation, including the enabling role of top management, the need for a champion promoting change, the creation of dedicated organizational units, and the need for new external knowledge sources.

\subsection{Capability rigidity and ambidextrous organizing}

Similar to structural rigidity, capability rigidity builds over time, especially in successful companies. Capability rigidity refers to rigidity in organizational routines, processes, and the overall culture related to how exploitation and exploration activities are conducted (e.g. Gilbert, 2005). In terms of routines and processes, rigidity builds through self-reinforcing pathdependency mechanisms (Sydow et al., 2009). When a company applies its capabilities successfully (resulting in new product launches), these capabilities acquire external and internal legitimacy and can attract more resources (Danneels et al., 2017). Continuing success and positive feedback on performance can lead to path-dependencies and lock-in, making it costly or near-impossible to transform routines and processes given the high levels of specialization and sunk investments. The cultural aspect of capability rigidity emerges in a similar way but has a broader reach in the company. An established culture of success in any context (e.g. innovation or R\&D) can become institutionalized over time, and both management and employees will begin to internalize it in their behaviours and how they apply routines and processes in exploration and exploitation (O'Reilly and Tushman, 2016).

Capability rigidity also tends to lead to an exploitative orientation given the feedback on successful performance in perfecting and iterating current operations. The management literature acknowledges this tendency over time - to drift towards exploitation at the expense of exploration - in the absence of disruptive attempts and preventive measures to avoid it 
(Birkinshaw et al., 2016; Davis et al., 2009). This also calls for understanding the tensions between contradictory demands for exploitation and exploration, which constitute a persisting paradox (Birkinshaw et al., 2016; Hansen et al., 2018; O’Reilly and Tushman, 2016).

There is major and accumulated evidence that capability rigidity can be overcome via the pursuit of organizational ambidexterity (Gilbert, 2005) - however, the ways to achieve this have been debated. Different ways to organize exploration and exploitation effectively include structural ambidexterity (exploitation and exploration conducted in different units), temporal/sequential ambidexterity (exploitation and exploration sequential in time), and contextual ambidexterity (exploitation and exploration conducted in the same place and at the same time) (Birkinshaw and Gupta, 2013; Chen, 2017).

\subsection{Combining open innovation and ambidexterity perspectives in organizational transformation}

In this study, we combine the open innovation approach with organizational ambidexterity in explaining how successful incumbents can fight their structural and capability rigidities. The studies combining the open innovation and ambidexterity perspectives already provide some arguments in this direction. Mortara and Minshall (2011) suggest that implementing open innovation is a feasible way to pursue ambidexterity, and Bröring and Herzog (2008) suggest that exploitation and exploration often correspond with the level of openness of innovation (the latter being more open). Further, the findings in the case studies of both Ferrary (2011) and Giannopoulou et al. (2011) generally suggest that adopting open innovation and ambidextrous organizing practices often go hand-in-hand. Indeed, companies with closed innovation models tend to handle both exploitation and exploration in-house, while open innovation embraces exploration that draws from both internal and external knowledge sources (Chesbrough and Bogers, 2014; Dahlander and Gann, 2010) as well as utilizes exploitation models that rely on external actors (e.g. licensing) (Lichtenthaler, 2009).

While the above-mentioned literature has identified a connection between organizational ambidexterity and open innovation, so far our understanding of the linkages between the two phenomena remain superficial, especially in the context of organizational transformation. However, as witnessed in the evidence discussed above, much of the issues in such change relate ultimately to reconfiguring how firms exploit and explore. Therefore, we expect that as firms embark in a transformation from a closed towards an open model of innovation, they also need 
to reconfigure and reorganize the way they search for explorative and exploitative innovation solutions. Thus, in the following empirical study we examine the potential of open innovation transformation and related organizational ambidexterity solutions to support overcoming structural and capability rigidity.

\section{Methodology}

We chose a single qualitative case study to examine how mature companies can break out of structural and capability rigidity by embarking on the open innovation journey. A qualitative approach allows a deep understanding of a complex phenomenon occurring in a specific, reallife setting (Eisenhardt and Graebner, 2007). Our goal was to develop an empirical framework to facilitate an in-depth inquiry into the case company's open innovation journey. Our focus was on the renewal of the company structure and capabilities from a process perspective, an investigation into the driving and resisting forces of change, and the coping mechanisms implemented. We applied an abductive research strategy based on revising and extending prior theory with the help of accumulated empirical insights (Dubois and Gadde, 2002).

A theoretical and purposive sampling strategy was used to select a case that would provide access to empirically relevant and information-rich data (Eisenhardt and Graebner, 2007). Consequently, our sampling decision was based on the following criteria: 1) the selected company should fit our conceptual definition of a Sleeping Beauty - that is, a firm with a long competitive track record and with well-established resources, technologies, and market brand; and 2) the company would have implemented open innovation to overcome the challenges to its renewal. Based on these criteria, we selected Swarovski, a leading global manufacturer of crystals. The company has a rich heritage of successful business.

Data collection was accomplished in three phases. In the first phase, we focused on Swarovski's open innovation journey to obtain a preliminary understanding of the practices, team activities, and roles implemented. In the second phase, we interviewed senior management and project managers and held numerous meetings with the open innovation team to understand Swarovski's open innovation journey. In the third phase, we presented our emerging interpretations to senior management to obtain validation of key events and gain additional insights. We collected data both retrospectively and in real time by focusing on events and triggers in the past and current strategies and managing practices related to the transition to open innovation. 
Between November 2016 and June 2017, we conducted 14 semi-structured interviews with selected senior managers from the Open Innovation Networks team, Innovation and Portfolio Management team, Human Resources, Procurement, R\&D, and Innovation Management. All had been involved in developing a strategy for a cultural transition to open innovation. The interviews lasted between 45 and 90 minutes and were transcribed verbatim, resulting in 267 pages of transcripts. We also drew on a range of other sources of data, including internal announcements about open innovation activities, documentation on open innovation projects, competitions held on intermediary platforms, press coverage, and data gathered from the company's open innovation platform. These multiple sources allowed data-triangulation and helped us to generate a holistic picture of Swarovski's transition process. We applied qualitative content analysis to the data, which facilitated their organization and coding and the identification of key events related to Swarovski's structure and capabilities, from the closed innovation and open innovation networks to the ecosystem engagement phase. Data analysis was conducted in three steps. First, we applied open coding to identify and distinguish the three innovation phases. Second, we open coded the interviews and confidential material to identify the dimensions corresponding to structural and capability rigidity. Third, we conducted axial coding to connect each innovation phase to the dimensions of boundaries and ambidexterity.

\section{Findings: Swarovski's open innovation journey}

This section describes the following three phases of Swarovski's innovation journey: (1) closed innovation, (2) open innovation networks, and (3) ecosystem engagement. In each phase, we present the dimensions of structural rigidity and capability rigidity. First, we observed the transformation of Swarovski's structural rigidity through the change from rigid boundaries (boundary preserving) to porous boundaries (boundary spanning and finally boundary expanding). Second, during this transition, we found that Swarovski evolved from static ambidexterity (compartmentalized, top-down exploration initiatives) to structural mode (dedicated exploration and exploitation functions) and then dynamic ambidexterity (integrated and changing exploration and exploitation). Finally, we identify external and internal driving forces for change and internal barriers to the closed and open innovation networks phases. For each phase, we discuss the specific change mechanisms that facilitated the transition.

INSERT FIGURE 1 ABOUT HERE 


\subsection{Protecting the 'crown jewels': Closed innovation phase}

The story of Swarovski began in the 1890s when jewel cutter Daniel Swarovski patented the first crystal-cutting machine, which revolutionized the jewellery business by creating a method for the mass production of crystals. To protect the invention from competitors Wattens, a small town in the Austrian Alps, was chosen for the Swarovski Company's headquarters, among other strategic choices (i.e. close proximity to water as a power source and to a fashion hub, Paris, with a high demand for crystal jewellery).

For almost 120 years, to around 2008, Swarovski had maintained its market leader position by applying a boundary preserving approach. This approach was characterized by maintenance of the status quo, a focus on in-house innovation, and protecting its proprietary technologies within tight organizational boundaries. To prevent knowledge leakage, the mission was to protect the 'crown jewels' (crystal producing, cutting and polishing processes). This mission had been passed from one generation to the next. As one senior manager explained, 'Swarovski has a history of being quite closed for quite some time. It was part of our DNA, doing everything inhouse'.

Its boundaries allowed only a few internal and external connections. The inflow of external knowledge was the responsibility of the respective head of the technology department, who was the main link with the external environment and the driving force behind external knowledge search and acquisition. The hierarchical structure and top-down approach was well established, and employees in Swarovski's technology departments were not encouraged to search for ideas outside its boundaries. As a top manager explained, 'If something comes from outside, it comes from the boss, and we do it ... He travelled through the world and ... looked at new technology and brought it to the departments'.

At that time, capability rigidity was reinforced by Swarovski's application of static ambidexterity (see also Raisch et al., 2009), characterized by a focus on excellence and stability in the core business units of crystal making and jewellery, quality, and refinement, with wellplanned top-down legitimated explorative initiatives. An example of Swarovski's well-planned exploratory initiative was a co-innovation approach with Christian Dior and the development of the Aurora Borealis effect. This collaboration secured Swarovski's success in the high fashion 
industry based on the development of a technique for coating the surface of the crystals to produce hallmark shimmering colours.

\subsection{Renewing crown jewels: Open innovation networks phase}

After almost a century of monopoly in crystal cutting, Swarovski received a wake-up call. In 2008 , with the onset of the global economic crisis, Swarovski observed a sudden increase in its competitors, who were offering similar high-end products at lower prices. This forced Swarovski to find new ways to differentiate itself, build new capabilities, and re-design its internal processes. Additional external change drivers were related to market changes; changing customer preferences; and global trends in terms of sustainability, personalization, digitalization, and technical advances (e.g. in new materials, wearable electronics, artificial intelligence and robotics). A top manager told us, 'So within two years, we were going from a monopoly situation into hyper competition. Meaning that services, product development, other types of offering, were getting more important to us as a point of differentiation from our competitors. And this meant that we needed a new way of thinking; we needed to better understand the customer and not just the customer but the consumers'.

The reality of the organizational changes - the need for reorganization and the need to identify new technological and market opportunities - was clear to employees, managers, and shareholders. Swarovski identified opportunities in cross-industry R\&D collaborations to tap into the knowledge and technologies of players from non-competing industries. Thus, Swarovski recognized the need to open up its boundaries to external ideas and technologies and involve different collaboration partners in different stages of the innovation process. Yet, it was challenging due to its long tradition of operating under the closed innovation approach, having a top-down management approach and a rather closed innovation cultural mindset. A top manager noted, robust strategies and new technologies were obvious and 'It was clear that the technology department had to open up to outside'.

In 2012, an organizational change was initiated where previously separated R\&D and selected marketing units were merged to form a Research, Design, and Innovation (RD\&I) department. This change represented a major step away from a technology-driven approach towards a customer-centric approach. Swarovski introduced several change mechanisms; one of them was to establish a dedicated team for external collaborations - open innovation networks. This team had a budget dedicated to searching externally for new ideas, developing cross-industry 
partnerships, and building a network of external partners. The team acted as a vehicle for boundary spanning among the broader strategic framework at that time. The role of the open innovation networks team was to define a new strategy for determining which practices and processes (including types of collaborative modes, knowledge sharing, and intellectual property management policies) to implement and where and how to search for new knowledge, technologies, and partnerships. To ensure purposive in-flows of knowledge, Swarovski defined eight exploratory search fields to discover new ideas and breakthrough technologies and in which to build collaborative projects. These included, for example, surfaces, application techniques, materials and combinations, and jewellery manufacturing technology. An example of these new openings was the development of the world's first solar-powered activity tracker in collaboration with a partner company that produces smartwatches and wearable gadgets. This collaboration was followed by another, which resulted in a product that uses built-in sensors to change colour when touched.

The open innovation networks team enabled the beginning of an open innovation culture among external and internal stakeholders. The team focused on building open engagement processes by communicating the company's needs and approaching partners directly via conferences and other external events. The director of open innovation networks explained his vision: 'We went completely across industries (...) we said we want to cross-fertilize, and our role was to communicate what we are looking for, to go outside, go to conferences, go to networks (...), and when we communicated the search fields to external environment, we were in the game of open innovation'. External activities were also related to establishing public visibility for Swarovski and positioning it as a technology partner, not 'just a maker of shiny crystals' (Scott, 2016). This turned out to be a stepping-stone and a 'peak decision to tell the world now what we are looking for'. By 2016, the open innovation networks team had gathered over a hundred cross-industry partners.

Internally, the team participated in the 'first date' meetings between the identified external party and the appropriate RD\&I department member. The team contributed to discussions on integrating technologies, intellectual property, joint collaboration, etc. but had no involvement in the later stages of the innovation process. It reasoned that to get other employees on board, it needed to develop strong external capabilities supported by best practice to promote internal awareness. To promote interest in open innovation activities, the team found external publicity and the recognition of open innovation networks to be quite effective. For example, in late 2015, Swarovski received an 'Open Innovation Award' in the 'Best Open Innovation Network' 
category from a German university. This attracted both external and internal recognition and increased the number of Swarovski employees and external actors interacting with the team.

This phase was characterized by Swarovski's effort to disrupt the rigidity of its organizational boundaries. This resulted in a model of structural ambidexterity which ensured the independence of the explorative unit (open innovation networks). However, the links to the exploitative parts of Swarovski remained, which allowed for cross-fertilization between the company's exploitative capabilities and new incoming ideas identified by the explorative open innovation unit.

\subsection{Tilting the playing field: Ecosystem engagement phase}

In 2016, with the continued growth of digitalization, technical advancements, and competition, Swarovski decided that initiatives to open up to external knowledge could not be the responsibility of only one team. Additional explorative initiatives were needed. To achieve this flexibility, Swarovski again redesigned its innovation process. As one of Swarovski's managers explained, '(...) now we see that this cannot be done by one person. That it should be a culture for everybody ... over the last years, we realized that we now need to prepare for the future, and we need to think again about future business models instead of just optimizing the existing ones'.

However, some of the forces resisting change from the previous phase persisted, and new forms of organizational rigidity emerged. First, due to the centralized RD\&I, there was an internal pressure for business units to compete for resources, resulting in internal competition and frustration. Second, the hierarchical structure and a rather closed innovation cultural mindset still existed in some parts. Swarovski's open innovation process was still being managed by a selected group of people, and there were limited possibilities for internal and external engagement and experimentation. Due to these aspects, senior management then decided that greater flexibility was needed to increase exploration and innovation. Several change mechanisms were introduced, which constituted the next phase of the transformation journey.

At the beginning of 2017, at the start of what we describe as the ecosystem engagement phase, the formal open innovation networks unit was closed down. Open innovation was defined and communicated to all employees as 'a cultural mindset and behaviour. The goal of this transition is to enrich ourfoundation for future innovation throughout the whole organization and ensure 
open innovation is not misunderstood as the responsibility of a team or department. Open innovation is rather a "way of working" for all of us' (internal employee information). The transition to empowering employees to become 'independent open innovation professionals' was launched with a new structure. First, Swarovski focused on internal changes to enable innovation and portfolio management (IPM) employees to build external networks of their own and to develop an open innovation mindset. Second, the new role of the former open innovation networks team was to facilitate a change roadmap and 'drive the evolution of culture of mutual support, experimentation and collaboration'. It involved cross-functional collaboration and knowledge sharing through internal workshops, the introduction of infrastructure tools (e.g. internal open innovation platform with portfolio of partners' technologies), and support systems for collaborative innovation and technology intelligence.

Third, Swarovski's innovation and HR departments put greater emphasis on the topic of cultural transition to greater openness in their strategic agendas. This included issues of empowering employees, education and training programs, and a reward system encouraging experimentation and external and internal collaboration. A senior director explained, 'we want to have a collaborative culture ... We are going more into rewarding teamwork, rewarding collaboration, rewarding experimentation. That's now really a big change we have still in front of us'. Furthermore, a more open and 'coopetitive' approach to external ecosystems was advocated especially for new technologies.

In addition, Swarovski created focus areas for selected specific business fields, such as digital jewellery and application platforms. These were run by innovation focus area leaders who had their own budgets for explorative and exploitative innovation initiatives. An interviewee explained that 'the leaders of focus areas were project leaders who needed to ask for budgets following the rules of a more hierarchical system. Now, they have own budget that empowers them'. To support the innovation focus area leaders and cultivate an open innovation culture, a training program was established that moved open innovation from a team-level effort to a company-level effort. Finally, Swarovski launched the innovation ventures program to build an ecosystem with start-ups in digital business areas.

The ecosystem engagement phase was characterized by the expansion Swarovski's boundaries and IPM employees' engagement with external ecosystems and working in cross-functional teams. Swarovski also created focus areas units to ensure purposive inflows and outflows of knowledge through organizational boundaries. Unlike the closed innovation phase, where 
boundaries, structure, and capabilities were rigid, in this phase changes to exploration and exploitation were linked to the opening of the organizational boundaries to the external environment. Thus, this development represented a move from boundary spanning to boundary expanding activities and continuous engagement with external ecosystems.

In this phase, Swarovski relied on dynamic ambidexterity - that is, deliberating over the choice of different types of ambidexterity (contextual, structural, sequential) based on the most feasible exploration and exploitation opportunities. At the business unit level, Swarovski applied contextual ambidexterity by empowering employees to explore new ideas and initiatives, often with the help of external ecosystem actors. The vision of Swarovski's IPM department was that 'it's now really the phase of making all people responsible and involved in innovation to build a network and to think of innovation as being open', a senior manager explained. By introducing focus areas run by focus area leaders, Swarovski applied deliberate spearheads of structural ambidexterity characterized by the separation of focus areas with dedicated budgets and individual structures and strategies. These focus area leaders also acted as boundary spanners. Within these areas, there were several innovation initiatives. According to the senior manager, 'all of them are now building their ecosystem of customers, consumers, and external partners'. He explained that 'it is very clear for us that there are innovation initiatives in our pipeline, where we can never be successful if we are not doing that in an open innovation way. Because there are innovation initiatives which require capabilities which are going beyond our [internal] capabilities (...) And in order to be open enough, in order to have kind of the possibilities to do explorative innovation, we needed to create a structure again for that'.

The different focus area teams were empowered to explore certain topics and were 'managed like internal start-ups with possibility of spin-offs'. Some of the focus areas were close to the existing core businesses, emphasizing exploitation. Other focus areas went beyond core businesses. In those cases, Swarovski relied on capabilities accessed through external ecosystem actors. These explorative focus areas were responsible for recognizing new opportunities where Swarovski would be perceived not only as a 'crystal company' but also as a company dedicated to technological innovation. For example, according to industry insiders, its recent explorative initiative has a potential to disrupt the whole industry. Swarovski has taken an active role by orchestrating the ecosystem. It has been collaborating with both complementors and competitors, research organizations, universities (including sponsorships of $\mathrm{PhDs}$ ), and start- 
ups and has been involved in several private-public initiatives and contracts and development agreements.

To manage the tensions between exploitation and exploration at the project level, sequential ambidexterity was applied - that is, new exploratory projects and initiatives were incubated to be brought back as exploitative projects. Overall, these changes showcase the transition to a dynamic mode of ambidexterity, where exploitative and explorative initiatives were launched in different parts of the organization and with external stakeholders. This provided further support for earlier efforts to internalize an open innovation mindset throughout Swarovski and facilitate both internal and external actors' involvement in the innovation process. This describes the current state of Swarovski, whose innovation journey is ongoing.

\section{Discussion and implications}

This article started by defining Sleeping Beauties, or mature companies with a long history of success, relatively little disruption, and competitive advantage based on core technologies and unique innovation capabilities and branding. Such companies exist in all industries and represent the last 'undisrupted' frontier of players that have perfected their niche strategies with scale and scope economies. The problem related to this type of success is organizational rigidity, which creeps into companies' structure and capabilities over time (Gilbert, 2005; Rawley, 2010; Danneels et al., 2017). Organizational rigidity renders firms slow or hesitant to react to change, makes their organizational culture unresponsive to outside ideas, and directs management to focus on exploitative refinement rather than explorative search. However, Sleeping Beauties eventually receive a wakeup call in the form of new entrants, new customer demands, or changes to the institutional environment. The traditional model of in-house innovation (i.e. closed innovation) may then be shown to be dysfunctional, and we argue that the principles of open innovation (Chesbrough, 2003), as well as organizational ambidexterity (O'Reilly and Tushman, 2016), will appear useful to achieve the necessary renewal.

In this study we have analysed Swarovski, a textbook example of a company with more than a hundred years of success, which recently faced a major market and technological disruption due to the entrance of new competitors, digitalization, and the economic crisis of 2008. Using insights from rich case study evidence, we showed how Swarovski overturned its organizational rigidity along two interdependent dimensions based on the development of a new innovation 
strategy. First, its structural rigidity was unravelled by a change from in-house development to a more flexible structure. This involved the ownership of innovation being spread across specialized functions and the organizational boundaries being made permeable to allow open innovation and external ecosystem engagement. Second, changes were implemented to overcome capability rigidity. The company's exploitation orientation and specialized R\&D function for exploration were subjected to structured change programs and, ultimately, dynamic ambidexterity involving various parts of the company. Overall, our results contribute to the open innovation and organizational ambidexterity streams of literature by examining how the two approaches complement each other during organizational transformation that aims to overcome key rigidities in firms' structure and capabilities.

The three phases that emerged from our analysis provide detailed evidence of the complementary roles of open innovation and ambidexterity. First, the closed innovation phase was a result of the accumulation of long-lasting innovation advantages. However, it has been suggested that it can lead to the innovation space becoming too narrow, mostly top-down, and compartmentalized among specific groups of decision makers and employees, allowing only a one-directional (inward) knowledge flow (c.f. Chesbrough, 2003; Herzog and Leker, 2010; Giannopoulou et al., 2011). In a context of accelerating industry transformation, a single approach to exploration largely ignores other sources of renewal potential. In our analysis we found that the closed innovation phase corresponded with that of static ambidexterity (cf. Raisch et al., 2009), where exploration is mostly driven and initiated as a well-planned top-down process. This has its advantages but leads to slow responsiveness to external change and a lack of diversity in ideas and initiatives.

To combat the challenges faced in the closed innovation phase, we witnessed a transformation to an open innovation networks phase. Here, we observed when a firm employs the classic principles of structural ambidexterity (i.e. structural separation of explorative units from exploitative ones, see e.g. O'Reilly and Tushman, 2004) as part of an open innovation initiative (in our case the open innovation networks team), the exploration of new technologies leads to new and radical innovation initiatives. Our study found that opting for separate explorative innovation units might encourage innovation ideas to emerge in different parts of the firm. Hence, different types of structural arrangements were employed to ensure links between explorative research units and the rest of the organization, supporting the integration principle discussed in the ambidexterity literature (Jansen et al., 2009). In addition, such arrangements, intertwined with opening up organizational boundaries to external knowledge, ensured the 
building of new capabilities and development of processes, practices, and routines for external knowledge exploration and organizational transformation. However, similar to that demonstrated recently by Hansen et al. (2018), we also witnessed that structural separation leads to integration problems. Due to its centralization, it may restrain other units from exploring innovation initiatives with external players on their own. Thus, we observed a further need to engage a broader range of employees in explorative initiatives and promote greater openness towards external knowledge, both associated with open innovation organizational and cultural transformation (Bröring and Herzog, 2008; de Araujo Burcharth et al., 2014; Herzog and Leker, 2010).

The issues discussed above led Swarovski to move to the phase of ecosystem engagement. Multiple innovation units were established and assigned with building innovation ecosystems, beyond Swarovski's traditional areas and solving simple technology problems. For example, employees were encouraged to build networks to search for new technology opportunities. All of these changes promoted dynamic ambidexterity, and pursuit of exploitation and exploration by actors in and around a flexible organization. Furthermore, there are features of contextual ambidexterity (see e.g. Birkinshaw and Gupta, 2013) where exploration and exploitation are handled in the same domains, retaining individual experts and managers the possibility to revolve between these two logics. The model utilized by Swarovski shows that it is possible to orchestrate this type of ambidexterity by providing a sufficient level of structure and direction while leaving room for contextual decisions as to whether and when to explore and exploit. Thus, it could be viewed as a type of dynamic ambidexterity (see also Chen, 2017 for discussion). This new approach has resulted in a newly launched ecosystem initiative and the development of a disruptive technology. Figure 2 summarizes our analysis of Swarovski's threephase transition process regarding the structural and capability dimension of organizational rigidity.

\section{INSERT FIGURE 2 ABOUT HERE}

While Swarovski's case is unique, we suspect that other mature companies and their practising managers experiencing transformation difficulties could learn from this study. We have shown that embarking on the journey to an open innovation model allowed Swarovski to deal with both structural and capability rigidity by opening its organizational boundaries and conducting both exploration and exploitation (Hansen et al., 2018). This type of gradual transformation could be 
imitated by other mature companies although the drivers and constraints and solutions to transformation problems will be firm-specific and will require tailored management initiatives. However, companies that are considering a similar transition should recall that Swarovski's effort was built on strong core technologies and a well-established brand. Established value combined with engagement with the external ecosystem can be used to leverage the capabilities within the organization and outside of it while retaining the ability to reap long-term brand and technology advantages.

This paper is not without limitations. First, this study assumes the transition from closed innovation to open innovation is a linear process. Yet, there are other studies that highlight the dynamics between open and closed models (Manzini et al., 2017). We also understand the methodological consideration of studying a company retrospectively. Future research could study other firms in mature industries that are impacted by digitalization, renewal, innovation, and globalization. Similarly, other studies could study the moment of implementing open innovation in relation to external technological threats.

\section{Achnowledgement}

The authors would like to express their gratitude to Swarovski for giving access to the case and the interview data. We would also like to thank participants at RADMA 2017 conference, numerous colleagues from LUT and JIBS as well as Marcus Holgersson from Chalmers, who have commented the earlier drafts of the paper. Finally, the authors would like to remark that the content of this article does not reflect the official opinion of Swarovski. Responsibility for the information and views expressed in the article lies entirely with the authors.

\section{References}

Altman, E. J. and Tushman, M. L. (2017) Platforms, Open/User Innovation, and Ecosystems: A Strategic Leadership Perspective. In: Furman, J. L., Gawer, A., Silverman, B. and Stern, S., (eds) Entrepreneurship, Innovation, and Platforms (Advances in Strategic Management): 177-207. Emerald Publishing Limited.

Birkinshaw, J. and Gupta, K. (2013) Clarifying the Distinctive Contribution of Ambidexterity to the Field of Organization Studies, Academy of Management Perspectives, 27, 287-298.

Bogers, M., Zobel, A.-K., Afuah, A., Almirall, E., Brunswicker, S., Dahlander, L., Frederiksen, L., Gawer, A., Gruber, M., Haefliger, S., Hagedoorn, J., Hilgers, D., Laursen, K., Magnusson, M. G., Majchrzak, A., McCarthy, I. P., Moeslein, K. M., Nambisan, S., Piller, F. T., Radziwon, A., RossiLamastra, C., Sims, J. and Ter Wal, A. L. J. (2017) The open innovation research landscape: 
established perspectives and emerging themes across different levels of analysis. Industry and Innovation, 24, 8-40.

Bröring, S., and Herzog, P. (2008) Organising new business development: open innovation at Degussa. European Journal of Innovation Management, 11, 3, 330-348.

Dahlander, L., and Gann, D. M. (2010) How open is innovation?. Research Policy, 39, 6, 699-709.

Danneels, E., Verona, G., and Provera, B. (2017) Overcoming the inertia of organizational competence: Olivetti's transition from mechanical to electronic technology. Industrial and Corporate Change, 27, 3, 595-618.

Chen, Y. (2017) Dynamic ambidexterity: How innovators manage exploration and exploitation. Business Horizons, 60, 385-394.

Chesbrough, H. (2003) Open innovation: The new imperative for creating and profiting from technology. Harvard Business School Press, Boston, Massachussetts.

Chesbrough, H., and M. Bogers. (2014) Clarifying an emerging paradigm for understanding innovation. In: Chesbrough H, Vanhaverbeke W, West J (eds) New Frontiers in Open Innovation, pp. 3-28. Oxford University Press, Oxford.

Chiaroni, D., Chiesa, V. and Frattini, F. (2010) Unravelling the process from closed to open innovation: evidence from mature, asset-intensive industries. $R \& D$ Management, 40, 222-245.

Danneels, E., Verona, G., and Provera, B. (2017) Overcoming the inertia of organizational competence: Olivetti's transition from mechanical to electronic technology. Industrial and Corporate Change, 27, 3, 595-618.

de Araújo Burcharth, A. L., Knudsen, M. P., and Søndergaard, H. A. (2014) Neither invented nor shared here: The impact and management of attitudes for the adoption of open innovation practices. Technovation, 34, 3, 149-161.

Di Minin, A., Frattini, F. and Piccaluga, A. (2010) Fiat: Open innovation in a downturn (1993-2003). California Management Review, 52, 132-159.

Dubois, A. and Gadde, L.E. (2002) Systematic combining: an abductive approach to case research. Journal of Business Research, 55,7, 553-560.

Duncan, R. (1976) The ambidextrous organization: Designing dual structures for innovation. In R. H. Killman, L. R. Pondy, and D. Sleven (Eds.), The Management of Organization, 1, 167-188. North Holland, New York.

Eisenhardt, K.M. and Graebner, M.E. (2007) Theory building from cases: Opportunities and challenges. Academy of Management Journal, 50, 1, 25-32.

Enkel, E., Gassmann, O., and Chesbrough, H. (2009) Open R\&D and open innovation: exploring the phenomenon. R\&D Management, 39, 4, 311-316.

Ferrary, M., (2011) Specialized organizations and ambidextrous clusters in the open innovation paradigm. European Management Journal, 29, 3, 181-192.

Gassmann, O., Enkel, E. and Chesbrough, H. (2010) The future of open innovation. R\&D Management, 40, 213-221.

Giannopoulou, E., Yström, A., and Ollila, S. (2011) Turning open innovation into practice: Open innovation research through the lens of managers. International Journal of Innovation Management, 15, 3, 505-524.

Gilbert, C. G. (2005) Unbundling the structure of inertia: resource versus routine rigidity. The Academy of Management Journal, 48, 741-763.

Hannan, M. T., and Freeman, J. (1984) Structural inertia and organizational change. American Sociological Review, 49, 2, 149-164.

Hansen, E. G., Wicki, S. and Schaltegger, S. (2018) Structural ambidexterity, transition processes, and integration trade-offs: a longitudinal study of failed exploration, R\&D Management, 1-25 DOI: 10.1111/radm.12339 
Herzog, P. and Leker, J., (2010) Open and closed innovation-different innovation cultures for different strategies. International Journal of Technology Management, 52, 3/4, 322-343.

Jansen, J. J., Tempelaar, M. P., Van den Bosch, F. A., and Volberda, H. W. (2009) Structural differentiation and ambidexterity: The mediating role of integration mechanisms. Organization Science, 20, 4, 797-811.

Kaplan, S. and Henderson, R. (2005) Inertia and incentives: Bridging organizational economics and organizational theory. Organization Science, 16, 5, 509-521.

Leonard-Barton, D. (1992) Core capabilities and core rigidities: a paradox in managing new product development. Strategic Management Journal, 13, 111-125.

Lichtenthaler, U. (2009) Outbound open innovation and its effect on firm performance: examining environmental influences. $R \& D$ Management, 39, 317-330.

Lifshitz-Assaf, H. (2017) Dismantling knowledge boundaries at NASA: The critical role of professional identity in open innovation. Administrative Science Quarterly, 63, 4, 746-782

Manzini, R., Lazzarotti, V. and Pellegrini, L. (2017) How to remain as closed as possible in the open innovation era: the case of Lindt \& Sprüngli. Long Range Planning, 50, 260-281.

Martin, B.R. (2016) Twenty challenges for innovation studies. Science and Public Policy, 43, 3, 432450.

Menon, T. and Pfeffer, J. (2003) Valuing internal vs. external knowledge: explaining the preference for outsiders, Management Science, 49, 4, 497-513.

Moellers, T., Visini, C., and Haldimann, M. (2018) Complementing open innovation in multi-business firms: practices for promoting knowledge flows across internal units. $R \& D$ Management. 1-20, DOI: $10.1111 / \mathrm{radm} .12343$

Mortara, L. and Minshall, T., (2011) How do large multinational companies implement open innovation? Technovation, 31, 10-11, 586-597.

O'Reilly, C. and Tushman, M. (2004) The ambidextrous organization. Harvard Business Review, 82, 4, 74.

O'Reilly, C. and Tushman, M. (2016) Lead and Disrupt: How to solve the innovator's dilemma: Stanford University Press.

O'Reilly, C. A. and Tushman, M. L. (2004) The ambidextrous organization. Harvard Business Review, 82, 4, 74 .

Papachroni, A., Heracleous, L. and Paroutis, S. (2016) In pursuit of ambidexterity: Managerial reactions to innovation-efficiency tensions. Human Relations, 69, 9, 1791-1822.

Radziwon, A. and Bogers, M. (2018) Open innovation in SMEs: Exploring inter-organizational relationships in an ecosystem. Technological Forecasting and Social Change.

Raisch, S., Birkinshaw, J., Probst, G., and Tushman, M.L. (2009) Organizational ambidexterity: Balancing exploitation and exploration for sustained performance, Organization Science, 20, 4, 685695.

Rawley, E. (2010) Diversification, coordination costs, and organizational rigidity: Evidence from microdata. Strategic Management Journal, 31, 8, 873-891.

Rohrbeck, R., Hölzle, K. and Gemünden, H.G. (2009) Opening up for competitive advantage-How Deutsche Telekom creates an open innovation ecosystem. $R \& D$ Management, 39, 4, 420-430.

Scott., M. (2016) Swarovski, Maker of All Things Bejeweled, Tries On a Hoodie, The New York Times, Oct 8, 2016

Salter, A., Criscuolo, P. and Ter Wal, A. L. J. (2014) Coping with open innovation: Responding to the challenges of external engagement in R\&D. California Management Review, 56, 77-94.

Shibata, T., Baba, Y., Kodama, M., and Suzuki, J. (2018) Managing ambidextrous organizations for corporate transformation: a case study of Fujifilm. $R \& D$ Management. DOI: 10.1111/radm.12326 
Sydow, J., Schreyögg, G. and Koch, J. (2009) Organizational path dependence: opening the black box. Academy of Management Review, 34, 689-709.

Tripsas, M. and Gavetti, G. (2000) Capabilities, cognition, and inertia: Evidence from digital imaging. Strategic Management Journal, 21, 1147.

Tushman, M. L., and O'Reilly, C. A. (1996) Ambidextrous organizations: Managing evolutionary and revolutionary change. California Management Review, 38, 8-30.

West, J., and Bogers, M. (2014) Leveraging external sources of innovation: a review of research on open innovation. Journal of Product Innovation Management, 31, 4, 814-831.

Wikhamn, B.R. and Styhre, A., (2017) Open innovation as a facilitator for corporate exploration. International Journal of Innovation Management, 21, 06, 750042.

Zobel, A. K., and Hagedoorn, J. (2018) Implications of open innovation for organizational boundaries and the governance of contractual relations. Academy of Management Perspectives. DOI: 10.5465/amp.2016.0175

Zollo, M. and Winter, S. G. (2002) Deliberate learning and the evolution of dynamic capabilities Organization Science, 13, 339-351.

Zynga, A., Diener, K., Ihl, C., Lüttgens, D., Piller, F., and Scherb, B. (2018) Making open innovation stick: a study of open innovation implementation in 756 global organizations: A large study of international companies shows that distinct routines and organizational structures differentiate organizations that succeed with open innovation. Research-Technology Management, 61, 4, 16-25. 


\section{Figure 1 Swarovski's open innovation journey}

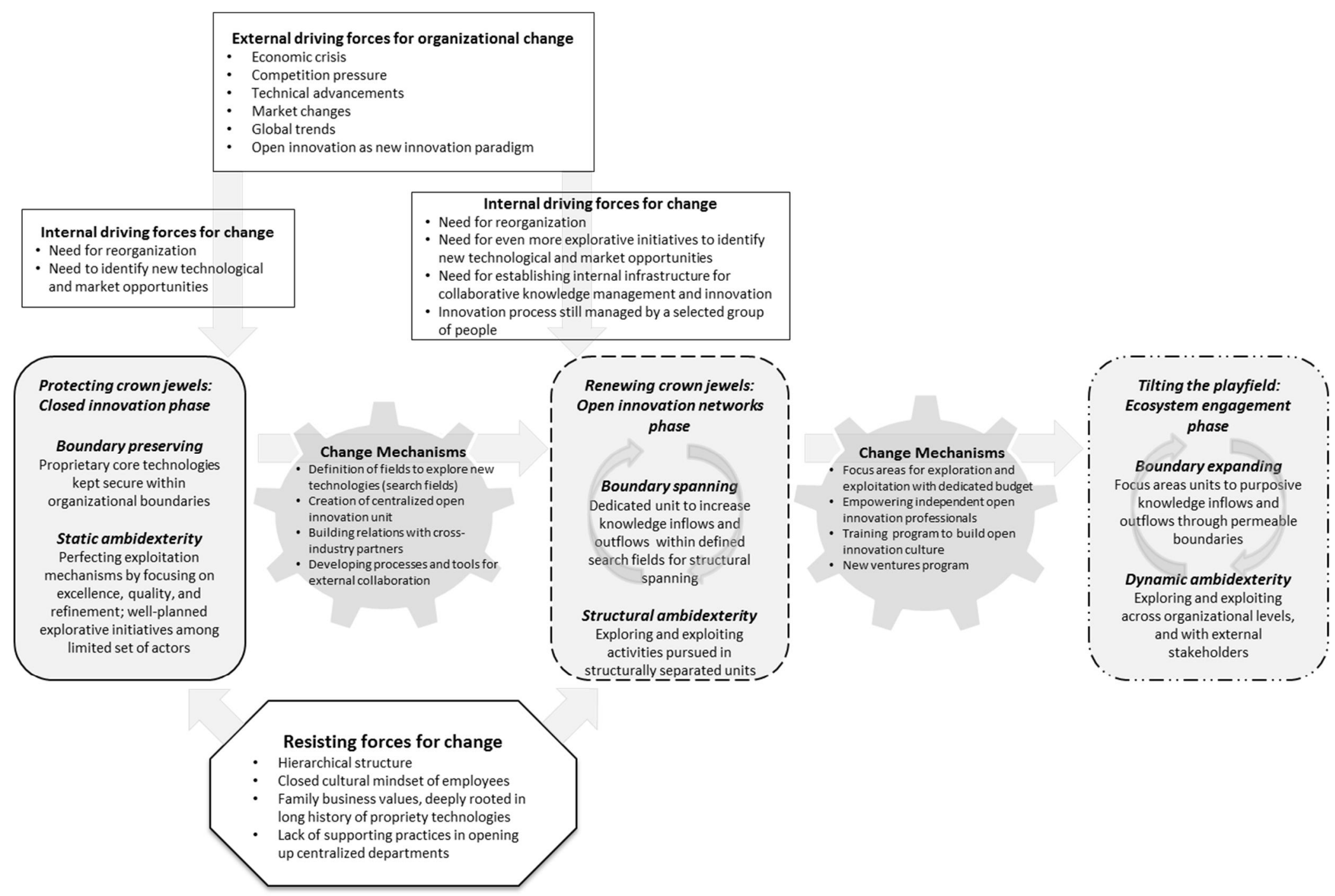


Figure 2 Organizational inertia: Structural rigidity and capability rigidity

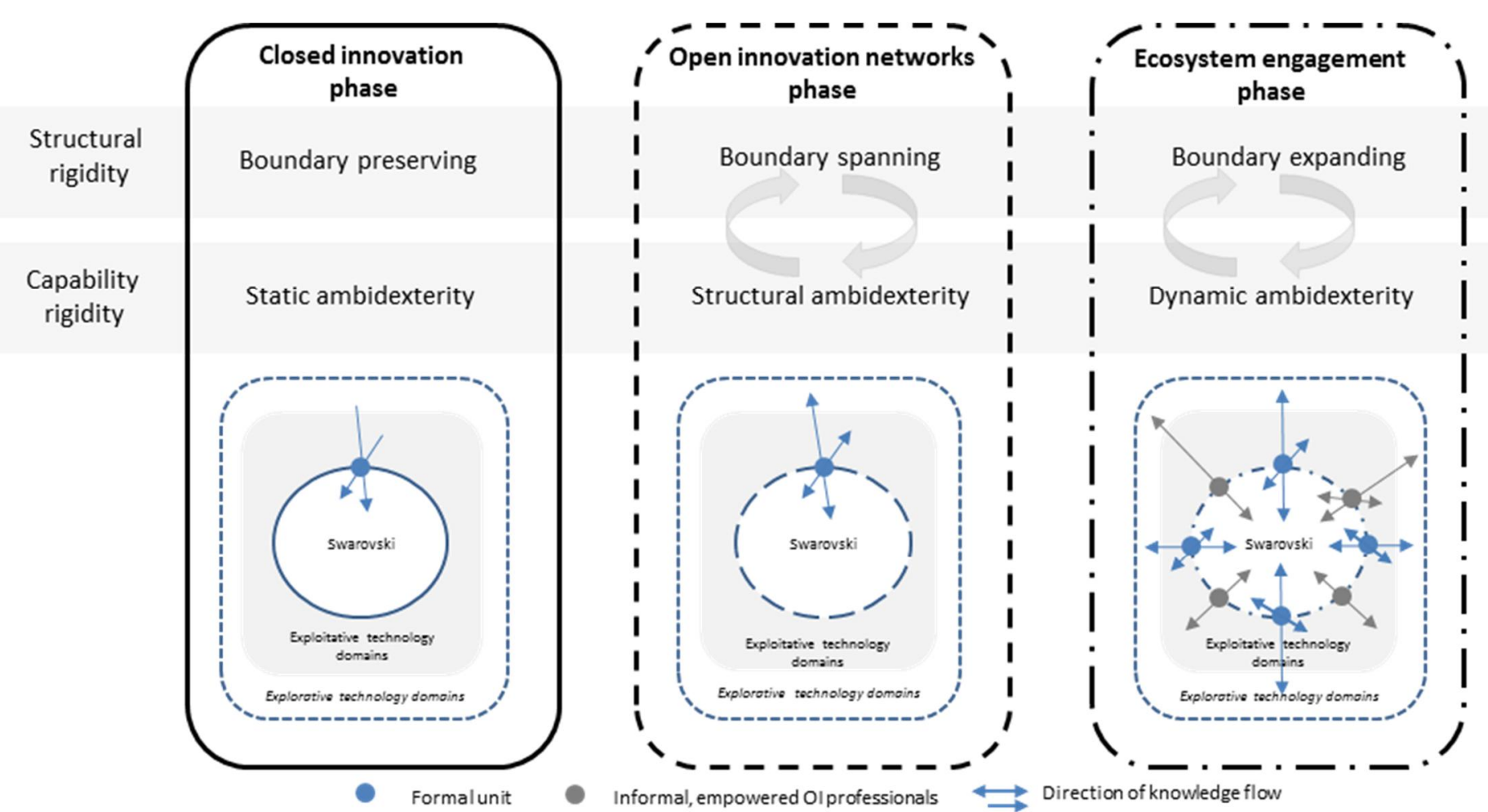

